\title{
(6) OPEN ACCESS \\ Long-term e-cigarette use and smoking cessation: a longitudinal study with US population
}

\author{
Yue-Lin Zhuang, Sharon E Cummins, Jessica Y Sun, Shu-Hong Zhu
}

Moores Cancer Center, University of California, San Diego, La Jolla, California, USA

\section{Correspondence to}

Dr Shu-Hong Zhu, Department of Family Medicine and Public Health, University of California, San Diego, 9500 Gilman Drive, MC 0905, La Jolla, CA 920930905, USA; szhu@ucsd.edu

Received 1 April 2016 Accepted 3 July 2016

\begin{abstract}
Background E-cigarettes have grown popular. The most common pattern is dual use with conventional cigarettes. Dual use has raised concerns that it might delay quitting of cigarette smoking. This study examined the relationship between long-term use of e-cigarettes and smoking cessation in a 2-year period.
\end{abstract}

Methods A nationally representative sample of 2028 US smokers were surveyed in 2012 and 2014. Longterm e-cigarette use was defined as using e-cigarettes at baseline and follow-up. Use of e-cigarettes only at baseline or at follow-up was defined as short-term use. Non-users did not use e-cigarettes at either survey. Quit attempt rates and cessation rates (abstinent for 3 months or longer) were compared across the three groups.

Results At 2-year follow-up, 43.7\% of baseline dual users were still using e-cigarettes. Long-term e-cigarette users had a higher quit attempt rate than short-term or non-users $(72.6 \%$ vs $53.8 \%$ and $45.5 \%$, respectively), and a higher cessation rate $(42.4 \%$ vs $14.2 \%$ and $15.6 \%$, respectively). The difference in cessation rate between long-term users and non-users remained significant after adjusting for baseline variables, $\mathrm{OR}=4.1$ (95\% Cl 1.5 to 11.4 ) as did the difference between long-term users and short-term users, OR=4.8 $(95 \% \mathrm{Cl}$ 1.6 to 13.9). The difference in cessation rate between short-term users and non-users was not significant, $\mathrm{OR}=0.9(95 \% \mathrm{Cl} 0.5$ to 1.4$)$. Among those making a quit attempt, use of e-cigarettes as a cessation aid surpassed that of FDA-approved pharmacotherapy. Conclusions Short-term e-cigarette use was not associated with a lower rate of smoking cessation. Long-term use of e-cigarettes was associated with a higher rate of quitting smoking.

\section{INTRODUCTION}

E-cigarettes have grown popular in recent years. The majority of e-cigarette users are current cigarette smokers. ${ }^{1} 2$ One reason e-cigarettes are so popular among smokers is that many believe that ecigarettes can help them quit smoking and, indeed, the use of e-cigarettes appears to be associated with intention to quit smoking. ${ }^{13-5}$ However, the US Food and Drug Administration (FDA) has not approved e-cigarettes as a cessation aid, although the UK has recently approved one brand. ${ }^{6}{ }^{7}$ To date, clinical trials testing the efficacy of e-cigarettes for smoking cessation have provided only limited evidence. $^{8}$

At the population level, there is concern that dual use of cigarettes and e-cigarettes could extend the use of both products. ${ }^{9}$ In fact, many dual users state that they use e-cigarettes at times and in places where they cannot smoke. ${ }^{5} 1011$ Dual use may reduce smokers' consumption of cigarettes, but it could lessen the urgency to quit smoking. ${ }^{12}$ This would extend the nicotine addiction and prolong the duration of cigarette smoking. If this is true, then the overall population effect of ecigarettes would be negative since duration of smoking poses a greater health risk than intensity of smoking. ${ }^{13}$

Many studies have examined the association of e-cigarette use and smoking cessation. ${ }^{14}$ However, only a few have investigated the effect of long-term use of e-cigarettes. Two studies reported high cessation rates among long-term e-cigarette users. ${ }^{15} 16$ However, these studies did not include a comparison group of smokers who did not use e-cigarettes. One study of state quitline callers reported that the quit rate was lower for those who used e-cigarettes than those who never used e-cigarettes. ${ }^{17}$ Among those who used e-cigarettes, those who used at least 1 month had a higher quit rate than those who did not use e-cigarettes for 1 month. Even though the use of a product for 1 month would generally not be considered to be long-term use, this study did find a difference between these two groups. A more recent study reported that the rate of quitting smoking was no different between those who had used e-cigarettes weekly for at least 6 months and those who did not use e-cigarettes. ${ }^{18}$ However, this study did not include those who used e-cigarettes for $<6$ months. Variations in study design and in selection of participants make it difficult to integrate these results. Moreover, none of these studies examined the effect of long-term e-cigarette use on smoking cessation with a sample representative of the general smoking population.

Using a longitudinal study design with a nationally representative sample of US adult smokers, the present study examined the effect of long-term ecigarette use by comparing long-term users with short-term users. Both groups were also compared against non-users. The study also gathered information on beliefs about e-cigarettes and the use of various tobacco and nicotine products. Smokers in the study were first surveyed in 2012 and then followed up in 2014. This time frame corresponded with the sharp rise in the use of e-cigarettes in the USA. $^{2} 19$ The 2-year duration allows for the examination of smokers who used e-cigarettes for an extended period of time.

\section{METHODS}

Data source

The University of California, San Diego surveyed a probability sample of the US population using GfK's KnowledgePanel between February and March, 2012. The probability-based panel was 
established using random-digit dialing and an address-based sampling frame $\mathrm{e}^{20}$ and provides representativeness similar to other US population surveys. ${ }^{21} 22$ Between February and March 2014, 2097 out of 3111 participants who were identified as current smokers at the 2012 baseline completed a follow-up survey $(67.4 \%)$. Of the 2097 , we excluded 56 who reported that they were never smokers in 2014 (despite saying they were current smokers in 2012) and 13 participants who did not report their current e-cigarette status in either $2012(n=10)$ or in $2014(n=3)$. Thus, the final effective sample size was 2028 .

\section{Measures}

Smokers were defined as those who had smoked at least 100 cigarettes in their lifetime and smoked every day or some days at the time of the survey. E-cigarette use was defined as those who used e-cigarettes in the last 30 days before the survey. Long-term e-cigarette users were those who used e-cigarettes at baseline and follow-up. Short-term e-cigarette users were those who used e-cigarettes only at baseline or only at follow-up. Non-e-cigarette users were those who did not use e-cigarettes at baseline or follow-up.

In addition, at follow-up e-cigarette users were asked if they had 'used e-cigarettes on at least 10 days (could be 10 days in a row or 10 days not in a row)' and if they had 'ever been a daily e-cigarette user for at least 1 month'.

At baseline, smokers were asked whether they planned to quit smoking. Anyone who was ready to quit smoking within 6 months was coded as having an intention to quit, following the convention of stage of change theory. ${ }^{23}$

The quit attempt rate was defined as the percentage of smokers who, at follow-up, had made at least one attempt to quit smoking that lasted for at least 24 hours in the past 2 years. The cessation rate was defined as the percentage of smokers at follow-up who had quit smoking for at least 3 months. Also, those who had quit smoking and those current smokers who made at least one quit attempt in the past 12 months before the 2014 survey were asked if they had used pharmacotherapies or e-cigarettes in their most recent quit attempt.

The use of any of FDA-approved cessation aids at follow-up, including nicotine replacement therapy (patches, gum, lozenges, spray or inhaler), bupropion and varenicline, were labelled as having used pharmacotherapy.

To assess their beliefs about e-cigarettes, the survey asked participants at follow-up how much they agreed or disagreed with the following three statements: 'Using e-cigarettes is harmful to one's health', 'E-cigarettes are less harmful to health than regular cigarettes' and 'E-cigarettes help people quit smoking'. In the analysis, strongly (agreed/disagreed) or somewhat (agreed/disagreed) were collapsed into dichotomous categories of agreed or disagreed.

\section{Analysis}

All percentages were weighted by population parameters based on the most recent US Current Population Survey. ${ }^{24} 25$ A surveyspecific poststratification adjustment was used to account for any survey non-responses, as well as any non-coverage, or undersampling and oversampling resulting from the survey-specific sampling design. The longitudinal panel produced an overall smoking prevalence for the USA of $20.7 \%$ in 2012 and $16.5 \%$ in 2014: the national estimates were $18.1 \%$ and $16.8 \%$ from the 2012 and 2014 National Health Interview Survey, respectively. $^{26} 27$

Logistic regressions were used to examine the effect of longterm use of e-cigarettes on quitting outcomes while adjusting for baseline social demographics, cigarettes per day (CPD) and intention to quit smoking. Beliefs about e-cigarettes and patterns of pharmacotherapy and e-cigarette use were compared across three e-cigarette use groups. CIs (95\%) were calculated on the basis of the sampling distribution of the corresponding summary statistic. A Wald $\chi^{2}$ test was used to determine significance. All calculations for this paper were generated using SAS V.9.4 software.

\section{RESULTS}

Figure 1 shows e-cigarette use status over time: of those who used e-cigarettes and cigarettes at baseline, $43.7 \%$ were still using e-cigarettes at the 2-year follow-up (ie, long-term ecigarette users) while 56.3\% stopped using e-cigarettes. Among those who did not use e-cigarettes at baseline, $19.4 \%$ were using e-cigarettes at follow-up.

Those who only used e-cigarettes at baseline or at follow-up are grouped together in the analysis and were defined as shortterm e-cigarette users. The remaining baseline smokers are classified as non-e-cigarette users.

Long-term users differed significantly from short-term users in their frequency of usage. Almost all the long-term users, $96.8 \%$, answered 'yes' when they were asked if they had used ecigarettes for at least 10 days in their life, compared to only $67.4 \%$ of short-term users $(p<0.001)$, and $67.3 \%$ of long-term users reported that they had used e-cigarettes daily for at least 1 month, compared to $32.2 \%$ of short-term users $(\mathrm{p}<0.001)$.
Figure 1 E-cigarette use status at baseline and follow-up.

Note: $95 \% \mathrm{Cl}$ is shown in parenthesis for each estimate.

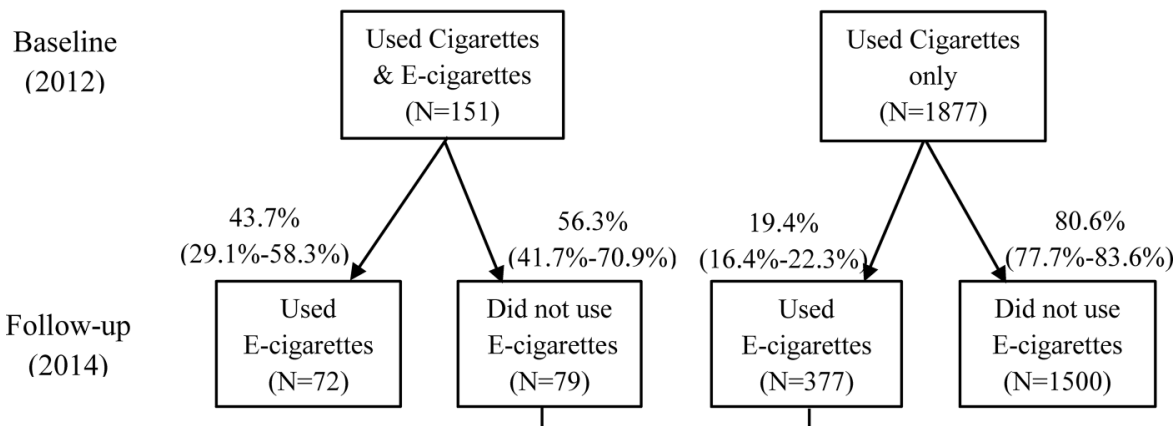

Long-term

Short-term

Nonusers 
Table 1 Demographics, cigarettes per day, and intention to stop smoking at baseline by length of e-cigarette use

\begin{tabular}{|c|c|c|c|}
\hline & 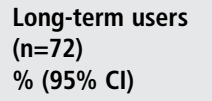 & $\begin{array}{l}\text { Short-term users } \\
(\mathrm{n}=456) \\
\%(95 \% \mathrm{Cl})\end{array}$ & $\begin{array}{l}\text { Non-users } \\
(\mathrm{n}=1500) \\
\%(95 \% \mathrm{Cl})\end{array}$ \\
\hline \multicolumn{4}{|l|}{ Gender } \\
\hline Men & 48.5 (27.0 to 69.9$)$ & $53.0(45.2$ to 60.7$)$ & 51.8 (47.7 to 55.9$)$ \\
\hline Women & 51.5 (30.1 to 73.0$)$ & 47.0 (39.3 to 54.8$)$ & 48.2 (44.1 to 52.3 ) \\
\hline \multicolumn{4}{|l|}{ Age } \\
\hline $18-24$ & 26.5 (2.9 to 50.0$)$ & 15.3 (8.2 to 22.4$)$ & $9.6(6.6$ to 12.5$)$ \\
\hline $25-44$ & $16.8(0.0 \text { to } 36.7)^{\mathrm{a}}$ & $40.0(31.9 \text { to } 48.1)^{b}$ & $40.5(36.3 \text { to } 44.8)^{b}$ \\
\hline $45-64$ & 51.0 (29.4 to 72.6$)$ & 38.8 (31.8 to 45.8 ) & 40.2 (36.4 to 44.0$)$ \\
\hline $65+$ & $5.8(1.1$ to 10.5$)$ & $5.9(3.9 \text { to } 7.9)^{\mathrm{a}}$ & $9.7(7.7 \text { to } 11.7)^{\mathrm{b}}$ \\
\hline \multicolumn{4}{|l|}{ Education } \\
\hline$\leq 12$ & 63.3 (44.7 to 81.9 ) & 56.5 (49.0 to 64.0$)$ & 58.9 (55.1 to 62.8$)$ \\
\hline$>12$ & 36.7 (18.1 to 55.3$)$ & 43.5 (36.0 to 51.0$)$ & 41.1 (37.2 to 44.9$)$ \\
\hline \multicolumn{4}{|l|}{ Ethnicity } \\
\hline NH-white & 77.3 (56.1 to 98.4 ) & $72.3(64.7$ to 79.9$)$ & 64.5 (60.3 to 68.7$)$ \\
\hline NH-black & $4.6(0.0 \text { to } 9.8)^{\mathrm{a}}$ & $12.3(6.5$ to 18.2$)$ & $15.2(12.0 \text { to } 18.5)^{b}$ \\
\hline Hispanic & - & $7.3(2.9 \text { to } 11.7)^{\mathrm{a}}$ & $13.6(10.3 \text { to } 17.0)^{b}$ \\
\hline Other & $18.1(0.0$ to 39.5$)$ & 8.1 (3.3 to 12.8 ) & 6.6 (4.5 to 8.7$)$ \\
\hline \multicolumn{4}{|l|}{ Cigarettes per day } \\
\hline$<15$ & 57.1 (36.0 to 78.3 ) & 56.7 (49.1 to 64.3$)$ & 63.4 (59.5 to 67.3$)$ \\
\hline$\geq 15$ & 42.9 (21.7 to 64.0$)$ & $43.3(35.7$ to 50.9$)$ & 36.6 (32.7 to 40.5$)$ \\
\hline \multicolumn{4}{|c|}{ Intention to stop smoking } \\
\hline No & 50.3 (28.8 to 71.9 ) & $66.6(59.2$ to 74.0$)$ & 72.3 (68.7 to 75.9$)$ \\
\hline Yes ( $<6$ months) & 49.7 (28.1 to 71.2 ) & 33.4 (26.0 to 40.8$)$ & 27.7 (24.1 to 31.3 ) \\
\hline
\end{tabular}

It should be noted that $40.1 \%$ of non-users reported that they had tried e-cigarettes at some point in their life. However, they were not using any e-cigarettes at time of survey in 2012 nor in 2014.

Table 1 shows the baseline demographics, cigarettes smoked per day and intention to quit smoking by e-cigarette use category. Those aged 25-44 were less likely to be long-term ecigarette users than short-term and non-users $(16.8 \%$ vs $40.0 \%$ and $40.5 \%$, respectively). Those aged $65+$ were more likely to be non-users than short-term users $(9.7 \%$ vs $5.9 \%)$. No gender or education differences were found among the three groups. The percentage of heavy smokers $(C P D \geq 15)$ did not differ significantly across e-cigarette use categories. Intention to quit smoking appeared to differ across groups, but the difference was not statistically significant.

The short-term e-cigarette use group comprised of two subgroups: those who used e-cigarettes only at baseline and those who used e-cigarette only at follow-up. The two subgroups were not different in either CPD (45.2\% vs $42.9 \%$ smoked $\geq 15$ $\mathrm{CPD}$ ) or intention to quit smoking (31.6\% vs $33.8 \%$ ), although the second subgroup had a higher proportion of 1824 -year-olds $(5.1 \%$ vs $17.2 \%)$ and of 65 years or older $(1.8 \%$ vs $6.7 \%)$ and a higher proportion who identified themselves as 'other' ethnicity (0.3\% vs $9.5 \%)$.

Table 2 shows beliefs about e-cigarettes. Long-term e-cigarette users were more likely to believe that e-cigarettes are less harmful than cigarettes compared to short-term users, who in turn were more likely to believe that than non-users. No significant difference was found between long-term and short-term ecigarette users on their beliefs that e-cigarettes are 'harmful to health', e-cigarettes 'help quitting' and e-cigarettes' 'secondhand
Table 2 Beliefs about e-cigarettes, assessed at 2014 follow-up survey

\begin{tabular}{llll}
\hline & $\begin{array}{l}\text { Long-term users } \\
\%(95 \% \mathrm{Cl}) \\
(\mathrm{N}=72)\end{array}$ & $\begin{array}{l}\text { Short-term users } \\
\%(95 \% \mathrm{Cl}) \\
(\mathrm{N}=454)\end{array}$ & $\begin{array}{l}\text { Non-users } \\
\%(95 \% \mathrm{Cl}) \\
(\mathrm{N}=1486)\end{array}$ \\
\hline $\begin{array}{l}\text { Beliefs } \\
\begin{array}{l}\text { Less harmful } \\
\text { than } \\
\text { cigarettes }\end{array}\end{array}$ & $96.2(92.1 \text { to } 100)^{\mathrm{a}}$ & $82.6(76.0 \text { to } 89.2)^{\mathrm{b}}$ & $70.8(67.0 \text { to } 74.6)^{\mathrm{c}}$ \\
$\begin{array}{l}\text { Harmful to } \\
\text { health }\end{array}$ & $27.3(6.7 \text { to } 47.8)^{\mathrm{a}}$ & $40.6(32.8 \text { to } 48.5)^{\mathrm{a}}$ & $54.3(50.2 \text { to } 58.5)^{\mathrm{b}}$ \\
$\begin{array}{l}\text { Helps with } \\
\text { quitting } \\
\text { Secondhand }\end{array}$ & $87.8(71.8 \text { to } 100)^{\mathrm{a}}$ & $82.8(76.0 \text { to } 89.7)^{\mathrm{a}}$ & $63.1(59.1 \text { to } 67.2)^{\mathrm{b}}$ \\
$\begin{array}{l}\text { vapour is } \\
\text { harmful }\end{array}$ & $13.9(0.0$ to 34.9$)$ & $12.4(7.6 \text { to } 17.1)^{\mathrm{a}}$ & $31.7(27.8 \text { to } 35.7)^{\mathrm{b}}$ \\
\hline
\end{tabular}

Different superscripts indicate significant difference in pairwise comparison.

vapour is harmful'. On the other hand, non-users generally held more negative beliefs about e-cigarettes than users did.

Table 3 presents the quit attempt rates and 3-month quit rates. Two analyses were performed to compare these rates: a univariate analysis and a multiple regression. Univariate analysis shows that long-term e-cigarettes users had a significantly higher quit attempt rate, 72.6\%, than non-users, 45.5\% $(\mathrm{p}<0.01)$. They also had a significantly higher quit attempt rate than shortterm users, $53.8 \%(\mathrm{p}<0.05)$. There was no significant difference between short-term users and non-users $(p=0.07)$.

Intention to quit smoking also predicted the quit attempt rate (71.1\% vs $38.6 \%)$, as did heavy smoking (40.9\% vs $52.5 \%)$. Among the demographic variables, higher education and the ethnic category 'other' predicted quit attempt.

The multiple regression showed similar results: long-term users had a significantly higher quit attempt rate than non-users $(\mathrm{OR}=2.94, \mathrm{p}<0.01)$, after adjusting for intention to quit smoking, CPD and demographic variables. The difference between short-term and non-users were not significant $(\mathrm{p}=0.07)$.

The results for the cessation rate, defined as quit for 3 months or more, show a similar pattern. The multiple regression results show that long-term users were more likely to quit smoking successfully than non-users $(\mathrm{OR}=4.14, \mathrm{p}<0.01)$, after adjusting for intention to quit smoking, CPD and demographic variables. The short-term users were not statistically different from non-users $(p=0.59)$.

The ORs shown in table 3 used non-users as the reference point. If the group of short-term users were used as the reference point, the OR of long-term against short-term users was 4.75 (95\% CI 1.62 to $13.94, \mathrm{p}<0.01)$.

The multiple regression shows that intention to quit smoking and CPD also independently predicted quitting for 3 months or more. Among demographic variables, only education remained a significant predictor after adjusting for other factors.

Table 4 shows the use of FDA-approved pharmacotherapy and the use of e-cigarettes in the last quit attempt. Long-term ecigarette users were no more likely than short-term or non-users to use pharmacotherapy. The overall rates were $19.5 \%$ for longterm users, $31.5 \%(8.2 \%+23.4 \%)$ for short-term users and $26.7 \%(22.1 \%+4.6 \%)$ for non-users. The use of e-cigarettes in the last quit attempt was also similar among long-term and short-term e-cigarette users (81.8\% vs $87.9 \%)$.

As mentioned earlier, many of those who did not use ecigarettes either at the 2012 survey or at the 2014 survey had 
Table 3 E-cigarettes use as predictors of quit attempt rate and cessation rate at follow-up, adjusted for baseline variables ( $N=2028)$

\begin{tabular}{|c|c|c|c|c|c|c|}
\hline & \multicolumn{3}{|c|}{ Quit attempt } & \multicolumn{3}{|c|}{ Quit for 3 months } \\
\hline & Per cent & OR $(95 \% \mathrm{Cl})^{*}$ & OR $(95 \% \mathrm{Cl}) \dagger$ & Per cent & OR $(95 \% \mathrm{Cl})^{*}$ & OR $(95 \% \mathrm{Cl}) \dagger$ \\
\hline \multicolumn{7}{|c|}{ E-cigarettes use status } \\
\hline Non-user & 45.5 & 1.00 & 1.00 & 15.6 & 1.00 & 1.00 \\
\hline Short-term & 53.8 & 1.39 (0.97 to 2.00$)$ & 1.43 (0.97 to 2.12 ) & 14.2 & 0.90 (0.56 to 1.43$)$ & 0.87 (0.53 to 1.43 ) \\
\hline Long-term & 72.6 & 3.16 (1.50 to 6.66$)$ & 2.94 (1.34 to 6.44$)$ & 42.4 & 3.98 (1.52 to 10.42$)$ & 4.14 (1.50 to 11.42$)$ \\
\hline \multicolumn{7}{|l|}{ Intention to quit } \\
\hline No & 38.6 & 1.00 & 1.00 & 12.1 & 1.00 & 1.00 \\
\hline Yes ( $<6$ months) & 71.1 & 3.91 (2.82 to 5.43 ) & 3.77 (2.69 to 5.30$)$ & 25.2 & 2.44 (1.64 to 3.62 ) & 2.37 (1.57 to 3.57 ) \\
\hline \multicolumn{7}{|l|}{ Cigarettes per day } \\
\hline$<15$ & 52.5 & 1.00 & 1.00 & 18.6 & 1.00 & 1.00 \\
\hline$\geq 15$ & 40.9 & 0.63 (0.47 to 0.84 ) & 0.68 (0.48 to 0.95$)$ & 11.8 & 0.58 (0.39 to 0.88 ) & 0.57 (0.38 to 0.85$)$ \\
\hline \multicolumn{7}{|l|}{ Gender } \\
\hline Men & 48.0 & 1.00 & 1.00 & 16.8 & 1.00 & 1.00 \\
\hline Women & 48.1 & 1.00 (0.75 to 1.34$)$ & 1.05 (0.78 to 1.43 ) & 15.2 & 0.89 (0.61 to 1.30$)$ & 0.84 (0.57 to 1.23 ) \\
\hline \multicolumn{7}{|l|}{ Age } \\
\hline $18-24$ & 45.8 & 1.00 & 1.00 & 13.0 & 1.00 & 1.00 \\
\hline $25-44$ & 52.7 & 1.32 (0.72 to 2.42 ) & 1.55 (0.82 to 2.95$)$ & 17.7 & 1.44 (0.64 to 3.22 ) & 1.80 (0.86 to 3.77 ) \\
\hline $45-64$ & 45.3 & 0.98 (0.55 to 1.75$)$ & 1.16 (0.63 to 2.14$)$ & 14.4 & 1.12 (0.51 to 2.46$)$ & 1.38 (0.66 to 2.88 ) \\
\hline $65+$ & 42.0 & 0.86 (0.45 to 1.66$)$ & 1.00 (0.50 to 2.00 ) & 19.5 & 1.63 (0.71 to 3.74 ) & 1.87 (0.86 to 4.09$)$ \\
\hline \multicolumn{7}{|l|}{ Education } \\
\hline$\leq 12$ & 43.7 & 1.00 & 1.00 & 13.3 & 1.00 & 1.00 \\
\hline$>12$ & 54.1 & 1.52 (1.15 to 2.01$)$ & 1.41 (1.05 to 1.90$)$ & 19.9 & 1.62 (1.11 to 2.38 ) & 1.53 (1.05 to 2.25$)$ \\
\hline \multicolumn{7}{|l|}{ Ethnicity } \\
\hline NH-white & 46.1 & 1.00 & 1.00 & 16.9 & 1.00 & 1.00 \\
\hline NH-black & 41.1 & 0.82 (0.51 to 1.30$)$ & 0.74 (0.45 to 1.21$)$ & 12.0 & 0.67 (0.31 to 1.43 ) & 0.57 (0.27 to 1.24$)$ \\
\hline Hispanic & 54.7 & 1.41 (0.83 to 2.41 ) & 1.19 (0.68 to 2.10$)$ & 14.2 & 0.81 (0.41 to 1.61 ) & 0.67 (0.34 to 1.30$)$ \\
\hline Other & 68.6 & 2.55 (1.42 to 4.58$)$ & 2.05 (1.02 to 4.12$)$ & 18.8 & 1.14 (0.53 to 2.46$)$ & 0.76 (0.37 to 1.55$)$ \\
\hline
\end{tabular}

tried e-cigarettes sometime in their life. Apparently, about $16.7 \%$ of non-users $(4.6 \%+12.0 \%)$ reported that they used e-cigarettes in their last quit attempt. The rate of using pharmacotherapy among this group is $26.7 \%(22.1 \%+4.6 \%)$.

If we treat e-cigarettes as a cessation aid, as these smokers reportedly did, then the use of cessation aids was significantly higher for long-term users and short-term users than for non-users $(81.8 \%, 87.9 \%$, and $38.7 \%$, respectively).

Overall, more quit attempts were aided by e-cigarettes than by FDA-approved pharmacotherapy. The proportion of using e-cigarettes only was $24.8 \%$ versus $17.8 \%$ for using pharmacotherapy only $(\mathrm{p}<0.05)$. The overall use for all quitting aids was $52.4 \%$.

\section{DISCUSSION}

This longitudinal study is the first to examine the long-term use of e-cigarettes and its association with quitting outcomes in a nationally representative sample of US smokers. The results show that prolonged use of e-cigarettes is associated with a higher smoking cessation rate, independent of the effect of baseline intention to quit smoking. Long-term e-cigarette users were more likely to perceive e-cigarettes as less harmful than cigarettes when compared to short-term e-cigarette users. Their perception of a lower level of harm is also associated with a greater likelihood of using e-cigarettes on a daily basis.

A large proportion, $44 \%$, of e-cigarette users among smokers in 2012 were still using e-cigarettes 2 years later. Despite an increasing number of reports suggesting that there are health risks associated with using e-cigarettes, ${ }^{28} 29$ among these longterm e-cigarette users, $96.2 \%$ perceived e-cigarettes as less harmful than cigarettes. This belief is a critical distinction between long-term users and short-term users. Both groups believed e-cigarettes are harmful, but the former were more likely to believe e-cigarettes were less harmful than cigarettes.

Table 4 Use of pharmacotherapy or e-cigarettes among those who made a quit attempt before 2014

\begin{tabular}{|c|c|c|c|c|}
\hline Pharmacotherapy/E-cigarettes & $\begin{array}{l}\text { Long-term users } \\
\%(95 \% \mathrm{Cl}) \\
(\mathrm{N}=38)\end{array}$ & $\begin{array}{l}\text { Short-term users } \\
\%(95 \% \mathrm{Cl}) \\
(\mathrm{N}=245)\end{array}$ & $\begin{array}{l}\text { Non-users } \\
\%(95 \% \mathrm{Cl}) \\
(\mathrm{N}=603)\end{array}$ & $\begin{array}{l}\text { Overall } \\
\%(95 \% \mathrm{Cl}) \\
(\mathrm{N}=886)\end{array}$ \\
\hline Pharmacotherapy only & 0 & 8.2 (2.2 to 14.1$)$ & 22.1 (17.1 to 27.0$)$ & 17.8 (13.9 to 21.7$)$ \\
\hline E-cigarettes only & 62.3 (34.9 to 89.7 ) & 56.4 (46.1 to 66.7$)$ & $12.0(7.5$ to 16.5$)$ & 24.8 (20.1 to 29.6 ) \\
\hline Both & $19.5(5.0$ to 34.0$)$ & 23.4 (15.5 to 31.2$)$ & 4.6 (2.8 to 6.5$)$ & 9.8 (7.3 to 12.2$)$ \\
\hline Any use & 81.8 (53.7 to 100$)$ & 87.9 (80.4 to 95.4$)$ & 38.7 (32.6 to 44.8 ) & 52.4 (47.0 to 57.8 ) \\
\hline
\end{tabular}


Interestingly, this is also the belief of an expert panel of tobacco researchers and the recent report by the Public Health England, ${ }^{30} 31$ although the methodology used to obtain estimates of relative risk in these documents has been criticised. ${ }^{32} 33$ There are indications, however, that the proportion of smokers who believe e-cigarettes are safer than cigarettes is decreasing over time. ${ }^{34}$ It is not clear if this change is beneficial to public health, given the findings of this study.

Smokers in the USA are not currently encouraged to use ecigarettes to help them quit smoking, which differs from the UK where one e-cigarette company has recently received approval for marketing them as cessation aids. ${ }^{6} 7$ Even so, this study shows that more than one-third of US smokers used e-cigarettes in their last quit attempt. In fact, about one-quarter of them used e-cigarettes as their only cessation aid. If we treat e-cigarette as a cessation aid, then the e-cigarette has significantly impacted the rate of cessation aid usage. No cessation aid introduced in the last decade has resulted in such a large increase in overall use of cessation aids. Even with the introduction of varenicline, a highly effective pharmacotherapy, the rate of using FDA-approved pharmacotherapies has hovered around $30 \%$ (similar to the $28 \%$ found in this study). The introduction of varenicline mainly displaced other therapies. ${ }^{35}$ In contrast, e-cigarettes do not appear to have simply displaced other therapies. Instead, they have contributed to a $50 \%$ increase in the rate of smokers using cessation aids (provided one classifies e-cigarettes as a cessation aid). This suggests that many smokers who would not otherwise use pharmacotherapies are using e-cigarettes to help themselves quit.

Data from the UK has shown a similar pattern. The use of e-cigarettes in smokers' last quit attempt has surpassed but not replaced NRT or varenicline in 2015 (39.5\% vs $26.4 \%$ or $6.5 \%$, respectively). ${ }^{36}$ As a result, the effect of e-cigarettes is likely to increase the total use of cessation aids.

Even though e-cigarettes have not been officially recognised as smoking cessation aids in the USA, a comparison with FDA-approved pharmacotherapy is instructive. Previous research has shown that the effect of pharmacotherapies in the realworld setting can only be detected if they are used for a sufficient period of time. ${ }^{37}$ Data from the present study support the importance of longer term use. For example, neither the quit attempt rate nor the cessation rate for short-term e-cigarette users was higher than for non-users. Since short-term users represent the majority of e-cigarette users, this explains why studies that lump all e-cigarette users do not detect any advantages for using e-cigarettes in smoking cessation.

It is important to point out that the population impact of e-cigarette use could still be negative despite the fact that the long-term use of e-cigarettes is associated with a higher smoking cessation rate. This would occur if short-term use, which is the majority among e-cigarette users, led to lower cessation rates than for non-use. The present study, however, found that this was not the case. The smoking cessation rate for short-term e-cigarette users was not statistically lower than for non-users. Moreover, the likelihood of current e-cigarette users turning to long-term e-cigarette use seems to be high (44\% from 2012 to 2014). It is not clear if this rate of transition to long-term use applies to any new e-cigarette users as we do not know what proportion of e-cigarette users at 2012 baseline survey would have qualified as long-term users already. An additional survey to follow this study sample is currently underway.

Previous studies have reported that the intensity of e-cigarette use (ie, daily use) is associated with higher smoking cessation rates. ${ }^{38-40}$ Biener and Hargraves further demonstrated that this is important even among those who have used e-cigarette for at least 1 month. In this study, long-term use, defined as using ecigarettes at both surveys, is highly correlated with using ecigarettes on a daily basis. Taken together, the evidence in these studies suggests that e-cigarettes need to be used consistently to be useful for smoking cessation, just as pharmacotherapy needs to be used consistently in order to be effective. ${ }^{37}$

This study has several limitations. While the data are based on a representative sample of the smoking population, the results are correlational. For example, rather than long-term ecigarette use causing smokers to quit, it is possible that longterm use is simply a proxy for motivation to quit smoking. This study, however, controlled for intention to quit smoking at baseline and found that long-term e-cigarette use still predicted quitting success. Another limitation is that the short-term use group was made up of two subgroups: those who used e-cigarettes only at baseline and those who used only at follow-up. The study found, however, despite some minor differences between these subgroups in demographics, there were no significant differences in CPD or intention to quit smoking at baseline, providing justification for collapsing them into one group. Finally, the measure of long-term use did not assess continuous use since it was based on two time points. There may have been more rapid changes in pattern of e-cigarette use between the two surveys that were not captured.

Despite these limitations, the findings of this study, with a representative sample of US smokers and a longitudinal study design, shed light on the issue of dual use of cigarettes and ecigarettes. Concerns have been raised that dual use might impede or delay attempts to quit smoking. This study found that those who used e-cigarettes longer term were more likely to quit smoking. Moreover, those who used short term were no less likely to quit smoking. This suggests that e-cigarette use is more likely, overall, to have a positive rather than a negative impact on smoking cessation.

\section{What this paper adds}

- Most e-cigarette users are current smokers. Concerns have been raised that prolonged dual use might impede or delay the attempt to quit smoking. This longitudinal study examined the relationship between long-term e-cigarette use and smoking cessation with a nationally representative sample of US smokers.

- Dual use of e-cigarettes and cigarettes was not associated with a lower smoking cessation rate.

- Long-term e-cigarette use was associated with a higher smoking cessation rate.

Acknowledgements The authors thank Lesley Copeland for her helpful comments on the earlier draft of the paper. The author list and acknowledgements include everyone who significantly contributed to the design, analysis, and writing of this work.

Contributors Study concept and design: S-HZ, Y-LZ and SEC. Acquisition of data: S-HZ, Y-LZ, SEC and JYS. Analysis and interpretation of the data: all authors. Drafting of the manuscripts: Y-LZ, SEC, S-HZ and JYS. Critical revision of the manuscript for important intellectual content: all authors. Statistical analysis: Y-LZ and S-HZ. Obtained funding: S-HZ and SEC. Study supervision: S-HZ.

Funding This study was supported by the National Cancer Institute of the National Institutes of Health under the State and Community Tobacco Control Initiative, Award Number U01CA154280. The content is solely the responsibility of the 
authors and does not necessarily represent the official views of the National Institutes of Health.

Disclaimer The study sponsor had no role in study design, data collection, analysis, interpretation or writing of the report.

Competing interests None declared.

Ethics approval This study was approved by the UCSD Human Research Protection Programme (IRB\#111664).

Provenance and peer review Not commissioned; externally peer reviewed.

Open Access This is an Open Access article distributed in accordance with the Creative Commons Attribution Non Commercial (CC BY-NC 4.0) license, which permits others to distribute, remix, adapt, build upon this work non-commercially, and license their derivative works on different terms, provided the original work is properly cited and the use is non-commercial. See: http://creativecommons.org/ licenses/by-nc/4.0/

\section{REFERENCES}

1 Delnevo CD, Giovenco DP, Steinberg MB, et al. Patterns of electronic cigarette use among adults in the United States. Nicotine Tob Res 2016;18:715-9.

2 McMillen RC, Gottlieb MA, Shaefer RMW, et al. Trends in electronic cigarette use among U.S. adults: use is increasing in both smokers and nonsmokers. Nicotine Tob Res 2015;17:1195-202.

3 Adkison SE, O'Connor RJ, Bansal-Travers M, et al. Electronic nicotine delivery systems: international tobacco control four-country survey. Am J Prev Med 2013;44:207-15.

4 Goniewicz ML, Lingas EO, Hajek P. Patterns of electronic cigarette use and user beliefs about their safety and benefits: an internet survey. Drug Alcohol Rev 2013;32:133-40.

5 Zhu S-H, Gamst A, Lee M, et al. The use and perception of electronic cigarettes and snus among the U.S. population. PLoS One 2013;8:e79332.

6 McKee S. MHRA licenses e-cigarette as a medicine. PharmaTimes. 2016. http://www.pharmatimes.com/Article/16-01-04/MHRA_licenses_e-cigarette_as_a_ medicine.aspx (accessed 31 Mar 2016).

7 Medicines and Healthcare Products Regulatory Agency. e-Voke $10 \mathrm{mg}$ electronic inhaler PL 42601/0003; e-Voke 15 mg electronic inhaler PL 42601/0004. (Nicotine). United Kingdom Product Assessment Report. Nicovations Limited, 2015. http://www.mhra.gov.uk/home/groups/par/documents/websiteresources/con616843. pdf (accessed 3 Mar 2016).

8 McRobbie H, Bullen C, Hartmann-Boyce J, et al. Electronic cigarettes for smoking cessation and reduction. Cochrane Database Syst Rev 2014;(12):CD010216.

9 Furlow B. US government warns against long-term dual use of conventional and e-cigarettes. Lancet Respir Med 2015;3:345.

10 Dockrell M, Morrison R, Bauld L, et al. E-cigarettes: prevalence and attitudes in Great Britain. Nicotine Tob Res 2013;15:1737-44.

11 Rutten LJF, Blake KD, Agunwamba AA, et al. Use of e-cigarettes among current smokers: associations among reasons for use, quit intentions, and current tobacco use. Nicotine Tob Res 2015;17:1228-34.

12 Grana R, Benowitz N, Glantz SA. E-cigarettes: a scientific review. Circulation 2014; 129:1972-86.

13 Doll R, Peto R. Cigarette smoking and bronchial carcinoma: dose and time relationships among regular smokers and lifelong non-smokers. J Epidemiol Community Health 1978;32:303-13.

14 Kalkhoran S, Glantz SA. E-cigarettes and smoking cessation in real-world and clinical settings: a systematic review and meta-analysis. Lancet Respir Med 2016:4:116-28.

15 Etter JF, Bullen C. A longitudinal study of electronic cigarette users. Addict Behav 2014;39:491-4.

16 Polosa R, Morjaria JB, Caponnetto P, et al. Effectiveness and tolerability of electronic cigarette in real-life: a 24-month prospective observational study. Intern Emerg Med 2014;9:537-46.
17 Vickerman KA, Carpenter KM, Altman T, et al. Use of electronic cigarettes among state tobacco cessation quitline callers. Nicotine Tob Res 2013;15: 1787-91.

18 Manzoli L, Flacco ME, Fiore M, et al. Electronic cigarettes efficacy and safety at 12 months: cohort study. PLoS One 2015;10:e0129443.

19 Caraballo RS, Jamal A, Nguyen $\mathrm{KH}$, et al. Electronic nicotine delivery system use among U.S. adults, 2014. Am J Prev Med 2016;50:226-9.

20 GfK. KnowledgePanel(R) Design Summary. GfK.com. 2013. http://www. knowledgenetworks.com/knpanel/docs/knowledgepanel(R)-design-summarydescription.pdf (accessed 31 Mar 2016).

21 Callegaro M, DiSogra C. Computing response metrics for online panels. Public Opin Q 2008;72:1008-32.

22 Yeager DS, Krosnick JA, Chang L, et al. Comparing the accuracy of RDD telephone surveys and internet surveys conducted with probability and non-probability samples. Public Opin Q 2011;75:709-47.

23 Prochaska J0, Velicer WF. The transtheoretical model of health behavior change. Am J Health Promot 1997;12:38-48.

24 Knowledge Networks. KnowledgePanel demographic profile; February 2012. 2012. http://www.knowledgenetworks.com/knpanel/docs/GfK-KnowledgePanel (R)-Demographic-Profile.pdf (accessed 1 Apr 2016).

25 US Census Bureau, US Bureau of Labor Statistics. The current population survey (CPS). Washington DC: U.S. Department of Commerce, 2013.

26 Agaku IT, King BA, Dube SR, et al. Current cigarette smoking among adults-United States, 2005-2012. MMWR Morb Mortal Wkly Rep 2014; 63:29-34.

27 Jamal A, Homa DM, O'Connor $\mathrm{E}$, et al. Current cigarette smoking among adultsUnited States, 2005-2014. MMWR Morb Mortal Wkly Rep 2015;64:1233-40.

28 Jensen RP, Luo W, Pankow JF, et al. Hidden formaldehyde in e-cigarette aerosols. N Engl J Med 2015;372:392-4.

29 Yu V, Rahimy M, Korrapati A, et al. Electronic cigarettes induce DNA strand breaks and cell death independently of nicotine in cell lines. Oral Oncol 2016;52:58-65.

30 Nutt DJ, Phillips LD, Balfour D, et al. Estimating the harms of nicotine-containing products using the MCDA approach. Eur Addict Res 2014;20:218-25.

31 McNeill A, Brose LS, Calder R, et al. E-cigarettes: an evidence update. Public Health England. 2015. https://www.gov.uk/government/uploads/system/uploads/ attachment_data/file/457102/Ecigarettes_an_evidence_update_A_report_ commissioned_by_Public_Health_England_FINAL.pdf (accessed 31 Mar 2016).

32 Gornall J. Public Health England's troubled trail. BMJ 2015;351:h5826.

33 McKee M, Daube M, Chapman S. E-cigarettes should be regulated. Med J Aust 2016:204:331.

34 Tan ASL, Bigman CA. E-cigarette awareness and perceived harmfulness: prevalence and associations with smoking-cessation outcomes. Am J Prev Med 2014; $47: 141-9$

35 Zhu S-H, Cummins SE, Gamst AC, et al. Quitting smoking before and after varenicline: a population study based on two representative samples of US smokers. Tob Control 2016;25:464-9.

36 West R, Brown J. Electronic cigarette use for quitting smoking in England: 2015. 2016. STS120722. http://www.smokinginengland.info/latest-statistics/ (accessed 18 Jul 2016).

37 Siahpush M, Shaikh RA, McCarthy $M$, et al. Association between duration of use of pharmacotherapy and smoking cessation: findings from a national survey. BMJ Open 2015;5:e006229.

38 Biener L, Hargraves JL. A longitudinal study of electronic cigarette use among a population-based sample of adult smokers: association with smoking cessation and motivation to quit. Nicotine Tob Res 2015;17:127-33.

39 Hitchman SC, Brose LS, Brown J, et al. Associations between e-cigarette type, frequency of use, and quitting smoking: findings from a longitudinal online panel survey in Great Britain. Nicotine Tob Res 2015;17:1187-94.

40 Chen C, Zhuang Y-L, Zhu S-H. E-cigarette design preference and smoking cessation: a U.S. population study. Am J Prev Med Published Online First: 19 Mar 2016. doi:10.1016/j.amepre.2016.02.002 